\title{
Modeling of nonlinear viscoelastic polymeric materials at their large periodic deformation
}

\author{
N. A. CHERPAKOVA - Altai State University, Russia - nadja-cherpakova@mail.ru \\ G. V. PYSHNOGRAI - Altai State University, Russia - pyshnograi@mail.ru \\ P. FILIP - Institute of Hydrodynamics, Academy of Sciences of Czech Republic • filip@ih.cas.cz \\ R. PIVOKONSKY - Institute of Hydrodynamics, Academy of Sciences of Czech Republic \\ - pivokonsky@ih.cas.cz
}

Érkezett: 2018. 07. 24. " Received: 24. 07. 2018. " https://doi.org/10.14382/epitoanyag-jsbcm.2019.1

\section{Abstract}

Analyzing the behavior of flows of polymers solutions and melts in the area of non-linear viscoelasticity allows to estimate more precisely the adequacy of the rheological model and to describe the material structure in more detail. Today a lot of models describe non-linear properties of polymeric materials rather accurately. However, the formulation of a uniform rheological mode remains open. Therefore this work considers the modified Vinogradov-Pokrovsky rheological model which formed the basis for numerical calculations for periodic deformation of shear flows of polymeric liquids with a large amplitude. The non-linear viscoelastic properties shown in the course of the research of behavior of polymeric material at large deformations were studied by means of the immediate analysis of time dependence of shear stresses which were calculated at various amplitudes. It was stated that when increasing the amplitude of deformation the response stops being the exact harmonica, and a "step" on the left-hand front appears. It manifests the nonlinear response of a sample. The work compares obtained theoretical dependences and the experimental data for $5 \%$ mass solutions of the polyethylene oxide in dimethylsulfoxide which was studied at harmonic deformations with the large amplitude reaching 40 relative units. These dependences were measured at $35^{\circ} \mathrm{C}$ and the frequency of $0.2 \mathrm{~Hz}$. Despite its simplicity, the modified Vinogradov-Pokrovsky rheological model shows good compliance with the experimental data. The results show that the chosen model adequately describes behavior of polymeric materials at large periodic deformations. Therefore this model may be applied for modeling more complex flows of fluid polymeric environments.

Keywords: rheology, rheological model, non-linear viscoelasticity, oscillations, shear, polymers solutions

Kulcsszavak: reológia, reológiai modell, nemlineáris viszkoelaszticitás, oszcilláció, nyírás, polimer oldatok
\end{abstract}

\section{Introduction}

A number of rheological models [1-4] are often applied to describe rheological features of polymeric materials at quite small periodic or stationary deformations. However, when processing solutions and melts of polymers we have to face with deformation of higher orders. Therefore, practical reasons and more precise methods of measurements e.g. at larger periodic deformations [5-7] cause the transition from analyzing the behavior of flows in the linear viscoelastic area to studying non-linear effects. It promises a more reliable assessment of prognostic properties of some rheological models as their applicability for different types of deformation is extended. Therefore now modeling rheological features in the non-linear viscoelastic area is getting more and more popular. In fact, the measurements at large periodic deformations allow to describe the material structure in more detail [6].

Nowadays there are a lot of rheological models some of which are still developing whereas others have already lost their relevance. The most prominent are: Gizekus model [1], LeonovProkunin model [2], the extended pom-pom model [3], the modified Vinogradov-Pokrovsky (mVP) model [4]. All of them
N. A. CHERPAKOVA

graduate student of the Altai State University, Barnaul, Russia, Area of scientific interests: rheology, polymer melt, mesoscopic theory.

G. V. PYSHNOGRAI

Doctor of Physical and Mathematical Sciences, Professor, of Altai State University, Barnaul, Russia, Area of scientific interests: rheology, polymer melt, mesoscopic theory.

P. FILIP

Professor Technology of Macromolecular Substances. The Institute of Hydrodynamics of the Czech Academy of Sciences, Prague, Czech Republic. Research activities - Rheology.

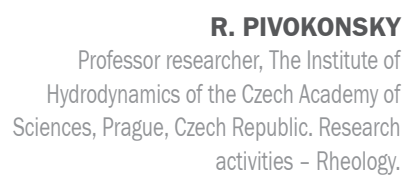

activities - Rheology describe well the linear effects at small periodic deformations and non-linear effects at large stationary deformations. Recently the new research has appeared and now it is developing rapidly. It studies the rheological behavior of polymeric liquids developed at periodic oscillations with a large amplitude [5]. This work will study the structural change of the material response while the amplitude of deformation increases. Primarily the work aims at checking the adequacy of the mVP rheological model.

As [6] shows, non-linear viscoelastic features which are observed when studying the behavior of polymeric material at large deformations may be interpreted via Lissajous figures or analyzing time dependencies of shear stresses obtained at various deformations. Thus the increase in oscillation amplitude means increase in nonlinearity of the sample response.

\section{Mathematical model}

The numeric calculations are based on the equations written down on the basis of the mVP rheological model [4]. The model is unique since it considers the tensor nature of the friction coefficient for beads which is defined by the induced anisotropy of a shift flow. The model looks as following: 
$\sigma_{i k}=-p \delta_{i k}+3 \frac{\eta_{0}}{\tau_{0}} a_{i k}$

$\frac{d}{d t} a_{i k}-v_{i j} a_{j k}-v_{k j} a_{j i}+\frac{1+(\kappa-\beta) I}{\tau_{0}} a_{i k}=\frac{2}{3} \gamma_{i k}-3 \frac{\beta}{\tau_{0}} a_{i j} a_{j k}$.

Here $\sigma_{i k}-$ a stress tensor; $p$ - hydrostatic pressure; $\eta_{o}$ and $\tau_{0}$ - initial values of shear viscosity and relaxation time for a polymeric component; $v_{i k}$ - velocity gradients tensor; $a_{i k}-$ the symmetric second rank tensor of anisotropy; $I=a_{i j}-$ first invariant of anisotropy tensor; $\gamma_{i k}=\left(v_{i k}+v_{k i}\right) / 2$ - symmetrized tensor of velocity gradients; $\kappa, \beta-$ phenomenological parameters of the model considering the sizes and the form of a macromolecular ball in macromolecule dynamical equations and which are connected by a ratio: $\kappa=1.2 \cdot \beta$, that corresponds with condition of independence of asymptotical behavior of stationary shear viscosity of the polymer molecular weight [4].

Based on Eq. (1) modeling of oscillations was carried out, both with large and small amplitudes. The polymeric sample is supposed to have been exposed to deformations with frequency $\omega$ under the harmonic law with the given amplitude $\gamma_{0}: \gamma(t)=\gamma_{0} \sin (\omega t)$. In this case only one component of velocity gradients tensor $v_{i j}$ is different from zero: $v_{12}(t)=\gamma_{0} \omega \cos (\omega t)$. The material response represents the tension-to-time dependence. According to the calculations, the periodic mode of oscillations is set quite rapidly in a polymeric system at deformation from immobility $\left(\sigma_{i k}(0)=0\right)$.

At the small amplitude shear stresses arising in the material are directly proportional to deformation that is they represent the exact harmonica. At periodic deformation of the material with the larger amplitude the response stops being the exact harmonica. The results of modeling (Fig. 1) and experiments [5] both confirm that.
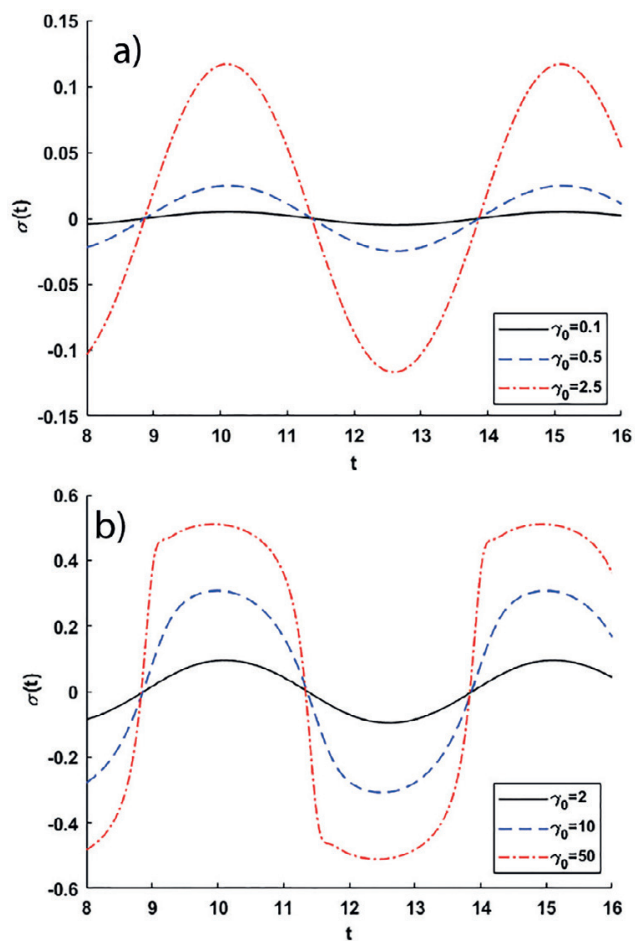

Fig. 1. Change of a response of material at increase in amplitude of deformation of material a) - small amplitudes; $b$ ) - large amplitudes)

1. ábra Anyag válaszának függése a deformáció amplitúdójától a) kis amplitúdók; b) nagy amplitúdók
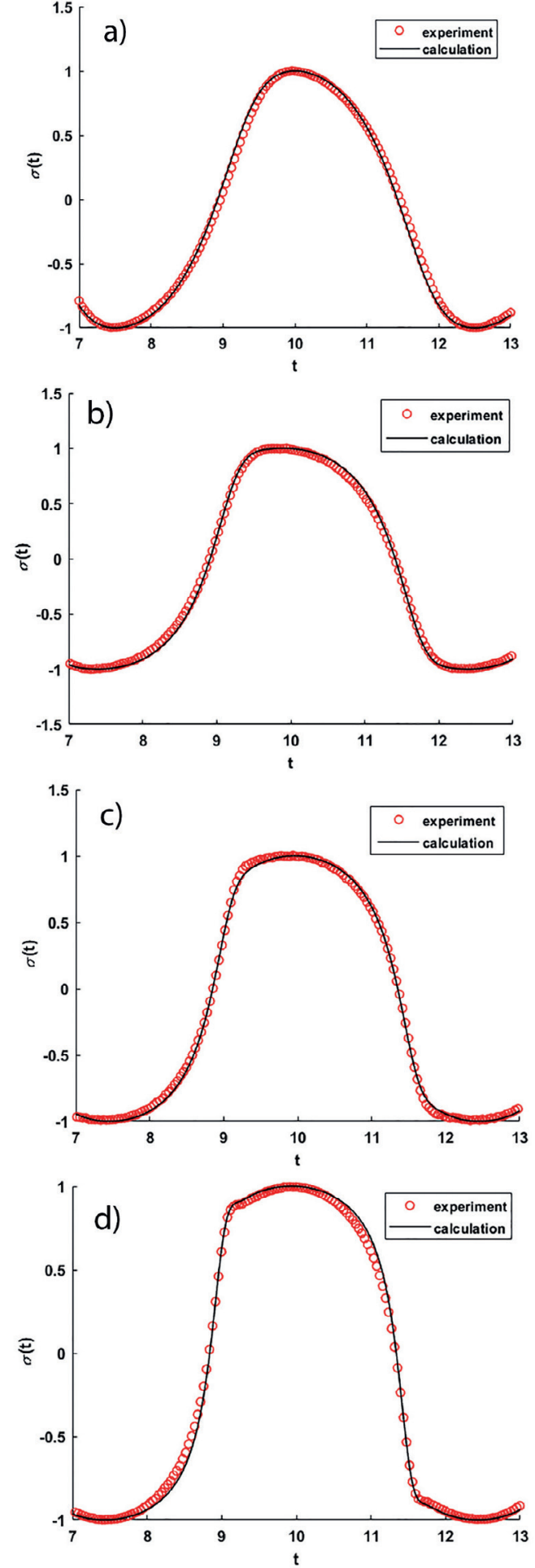

Fig. 2. Comparison of theoretical dependence and the experimental data for the normalized shear stresses $\sigma(t)$ in the set mode with various relative amplitudes of deformation a) - 5; b) - 10; c) - 20; d) - 40)

2. ábra Normalizált nyírófeszülttség $\sigma(t)$ összehasonlítása elméleti összefüggések és mért adatok között a) - 5; b) - 10; c) - 20; d) - 40)

\section{Comparing modeling results and the experiment}

A large number of works, referred to in [5-7], is devoted to a research of transient and stationary rheological features at large periodic deformations. In the experimental data [7] the 5\% 
mass solution of polyethylene oxide in a dimethylsulfoxide was exposed to deformation. The polymeric solution was exposed to harmonic deformation at large amplitude $\gamma_{0}$, sequentially reaching values of $50 \%, 100 \%, 500 \%, 1000 \%, 2000 \%$ and $4000 \%$ at frequency $\omega=0.2 \mathrm{~Hz}$.

The application of the mVP rheological model was checked for efficiency by optimizing model parameters $\kappa=0.045$; $\beta=0.038 ; \tau_{0}=0.21 \mathrm{sec} ; \eta_{0}=87.3534$ Pas.s. in the linear area (at small periodic deformations). Further the behavior of the model with the found parameters was compared to the results of experiments at large periodic deformations.

Fig. 2 shows the comparison of the established dependences of the normalized response calculated via the Runge-Kutta method with the experimental data from [7].

It is noticeable that the left and right fronts of oscillations are deformed differently at increased relative amplitude. The graph of experimental dependences shows the emergence of a step at the increased amplitude. At increased $\gamma_{0}$ the right front deviates from harmonica without a step. The model describes this effect rather precisely (Fig. 2). The comparisons between the obtained results and previous experimental data mean that the model provides for a quite precise description of polymeric materials at large periodic deformations.

\section{Conclusions}

The work provided for modeling a non-linear viscoelasticity of the polymeric material at its large periodic deformations via the mVP model. The results were compared with the experimental data of $5 \%$ mass solution of polyethylene oxide in dimethylsulfoxide which was studied at harmonic deformations of large amplitude reaching 40 relative units measured at $35^{\circ} \mathrm{C}$ and the frequency of $0.2 \mathrm{~Hz}$ [5].

Nonlinearity of the studied sample manifests itself in the response distortion for the material as it stops being the exact harmonica. The considered model allows to model the non-linear effects arising at increased amplitude of material deformation. It is also possible to use this model for modeling more complex flows of fluid polymeric media.

It is curious that such a simple model as Eq. (1) which considers only one relaxation process complies so greatly to the experimental data. When describing the non-linear dependence of shift viscosity and normal stresses of the firstorder difference, this model shows only qualitative compliance of calculated dependences and the experimental data $[4,8,9]$.

Further research plans to modify the considered model for a multimode case in order to increase the accuracy of the results. Also the model will be studied via the Lissajous figures.

\section{Acknowledgments}

One of the authors (CheNA) acknowledgment financial support of the Russian Foundation for Basic Research (RFBR) under grant 18-31-00030.

The authors (P.F. and R.P.) wish to acknowledge the Grant Agency CR for the financial support of Grant Project No. 17$26808 S$ and the Institutional Research Plan RVO 67985874.

\section{References}

[1] Giesekus, H. (1982): A simple constitutive equation for polymer fluids based on the concept of deformation-dependent tensorial mobility. Journal of Non-Newtonial Fluid Mechanics, 1982. Vol. 11. pp. 69-109. https://doi.org/10.1016/0377-0257(82)85016-7

[2] Leonov, A. I. (1992): Analysis of simple constitutive equations for viscoelastic liquids. Journal of Non-Newtonial Fluid Mechanics, 1992. Vol. 42. pp. 323-350. https://doi.org/10.1016/0377-0257(92)87017-6

[3] Pivokonsky, R. - Filip, P. (2014): Predictive/fitting capabilities of differential constitutive models for polymer melts - reduction of nonlinear parameters in the eXtended Pom-Pom model. Colloid and Polymer Science, 2014. 292. pp. 2753-2763. https://doi.org/10.1007/s00396-014-3308-7

[4] Merzlikina, D. A. - Pyshnograi, G. V. - Pivokonskii, R. - Filip P. (2016): Rheological model for describing viscometric flows of melts of branched polymers. Journal of Engineering Physics and Thermophysics, Vol. 89, No. 3, May, 2016, pp. 652-659. https://doi.org/10.1007/s10891-016-1423-7

[5] Ilyin, S. O. - Malkin, A. Ya. - Kulichikhin, V. G. (2014): Application of large amplitude oscillatory shear for the analysis of polymer material properties in the nonlinear mechanical behavior. Polymer Science Series A, 2014. V.56. pp. 98-110. https://doi.org/10.1134/S0965545X14010039

[6] Ewoldt, R. H. - Hosoi, A. E. - McKinley, G. H (2008): New measures for characterizing nonlinear viscoelasticity in large amplitude oscillatory shear. Journal of Rheology, Vol. 52, No. 6. https://doi.org/10.1122/1.2970095

[7] Pivokonsky, R. - Filip, P. - Zelenkova, J. (2017): Two Ways to Examine Differential Constitutive Equations: Initiated on Steady or Initiated on Unsteady (LAOS) Shear Characteristics. Polymers. 2017. V.9. pp 205 https://doi.org/10.3390/polym9060205

[8] Koshelev, K. B. - Pyshnograi, G. V. - Tolstykh, M. Y. (2015): Modeling of the three-dimensional flow of polymer melt in a convergent channel of rectangular cross-section. Fluid Dynamics. 2015. Vol. 50. No. 3. pp 315321. https://doi.org/10.1134/S0015462815030011

[9] Pyshnograi, G. V. - Gusev, A. S. - Pokrovskii, V. N. (2009): Constitutive equations for weakly entangled linear polymers. Journal of Non-Newtonian Fluid Mechanics. 2009. V. 164. No. 1-3. pp 17-28.

https://doi.org/10.1016/j.jnnfm.2009.07.003

Ref.

Cherpakova, N. A. - Pyshnograi, G. V. - Filip, P. - Pivokonsky, R. Modeling of nonlinear viscoelastic polymeric materials at their large periodic deformation

Építőanyag - Journal of Silicate Based and Composite Materials, Vol. 71, No. 1 (2019), 2-4. p. https://doi.org/10.14382/epitoanyag-jsbcm.2019.1

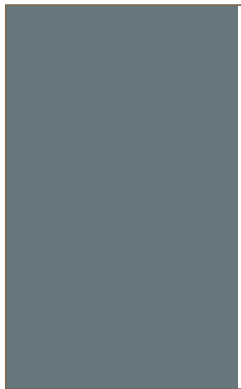

13 - 16 October 2019 Maastricht, The Netherlands www.europm2019.com

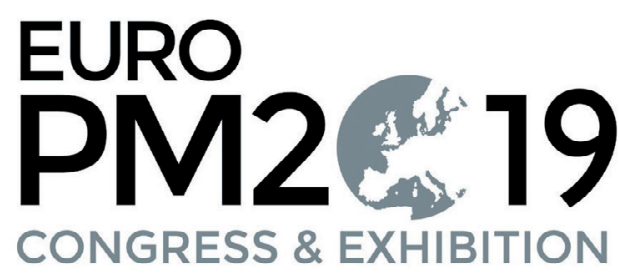

